\title{
Review Article \\ Role of Dehalogenases in Aerobic Bacterial Degradation of Chlorinated Aromatic Compounds
}

\author{
Pankaj Kumar Arora and Hanhong Bae \\ School of Biotechnology, Yeungnam University, Gyeongsan, Gyeongbuk 712-749, Republic of Korea \\ Correspondence should be addressed to Pankaj Kumar Arora; arora484@gmail.com and Hanhong Bae; hanhongbae@ynu.ac.kr
}

Received 29 July 2014; Revised 16 October 2014; Accepted 22 October 2014; Published 13 November 2014

Academic Editor: Davide Vione

Copyright (C) 2014 P. K. Arora and H. Bae. This is an open access article distributed under the Creative Commons Attribution License, which permits unrestricted use, distribution, and reproduction in any medium, provided the original work is properly cited.

This review was conducted to provide an overview of dehalogenases involved in aerobic biodegradation of chlorinated aromatic compounds. Additionally, biochemical and molecular characterization of hydrolytic, reductive, and oxygenolytic dehalogenases was reviewed. This review will increase our understanding of the process of dehalogenation of chlorinated aromatic compounds.

\section{Introduction}

Chlorinated aromatic compounds including chlorobenzenes, chlorobenzoates, chlorophenols, chloroanilines, hexachlorobenzene, polychlorinated biphenyl, chloronitrophenols, chloroaminophenols, and atrazine comprise a major group of environmental pollutants that are used in the manufacture of dyes, drugs, pesticides, and other industrial products [1-7]. These compounds are stable due to the presence of carbonchlorine bonds; therefore, the cleavage of carbon-chlorine bonds is a critical step in their degradation. Such cleavage may occur via two ways: (i) by spontaneous dechlorination of an unstable intermediate of unrelated enzymatic reactions [8] and (ii) by enzymatic dechlorination where the carbonchlorine bond cleavage is catalyzed by specific enzymes [918].

Spontaneous dehalogenation occurs due to the chemical decomposition of an unstable intermediate after ring cleavage of chlorinated aromatic compounds [8]. This phenomenon has been observed in degradation of gammahexachlorocyclohexane where chlorohydroquinone-1,2-dioxygenase catalyzed the cleavage of the chlorohydroquinone to an acylchloride that spontaneously converted to maleylacetate with release of $\mathrm{HCl}$ [19]. Another example includes spontaneous dehalogenation during the degradation of chlorobenzoic acids [8]. Chlorobenzoic acids initially converted to chlorocatechols which were further degraded via modified ortho-cleavage pathway [8]. In this pathway, dehalogenation occurs spontaneously during further metabolism of ring-cleavage products [8].

Enzymatic dehalogenation involves the removal of chlorine atoms from aromatic rings by either hydrolytic, reductive, or oxygen dependent dehalogenation [9]. Hydrolytic dehalogenation includes replacement of the chlorine atom with the hydroxyl group in the aromatic ring. This hydroxyl group is derived from water [9]. Reductive dehalogenation involves replacement of the chlorine atom with a hydrogen atom [9]. Oxygenolytic dehalogenation involves replacement of the chlorine atom with a hydroxyl group containing an oxygen atom derived from $\mathrm{O}_{2}$ [9]. Oxygenolytic dehalogenation is further divided into two classes, monooxygenase type dehalogenation and dioxygenase type dehalogenation [9]. Monooxygenase type dehalogenase adds one atom of oxygen to chlorinated compounds to remove the chlorine atom [9]. Dioxygenase type dehalogenase adds two atoms of oxygen into the substrate to remove the chlorine atom [9]. Dehalogenases involved in the aerobic dehalogenation of aromatic compounds are summarized in Table 1. In this review, we provide a detailed description of well-studied dehalogenases.

1.1. 4-Chlorobenzoyl-CoA Dehalogenase. 4-ChlorobenzoylCoA dehalogenase is the best studied hydrolytic aromatic 
TABLE 1: A list of various dehalogenases involved in the aerobic biodegradation of chlorinated aromatic compounds.

\begin{tabular}{|c|c|c|c|c|}
\hline Dehalogenase & $\begin{array}{l}\text { Enzyme } \\
\text { commission } \\
\text { number }\end{array}$ & Class & Reaction catalyzed & Reference \\
\hline 4-Chlorobenzoyl-CoA dehalogenase & $\mathrm{EC}=3.8 .1 .7$ & Hydrolytic & $\begin{array}{l}\text { Converts 4-chlorobenzoyl-COA to } \\
\text { 4-hydroxybenzoyl CoA }\end{array}$ & {$[10]$} \\
\hline 4-Chlorobenzoate dehalogenase & $\mathrm{EC}=3.8 .1 .6$ & Hydrolytic & $\begin{array}{l}\text { Converts } 4 \text {-chlorobenzoate to } \\
\text { hydroxybenzoate }\end{array}$ & [11] \\
\hline Chlorothalonil dehalogenase & $\mathrm{EC}=3.8 .1 .-$ & Hydrolytic & $\begin{array}{l}\text { Converts 2,4,5,6-tetrachloroisophthalonitrile } \\
\text { (chlorothalonil) to } \\
\text { 4-hydroxy-trichloroisophthalonitrile }\end{array}$ & {$[12]$} \\
\hline Atrazine chlorohydrolase & $\mathrm{EC}=3.8 .1 .8$ & Hydrolytic & $\begin{array}{l}\text { Converts atrazine (2-chloro-4-(ethylamino)- } \\
\text { 6-(isopropylamino)-1,3,5-triazine) to } \\
\text { 2-hydroxy-4-(ethylamino)-6- } \\
\text { (isopropylamino)-1,3,5-triazine }\end{array}$ & {$[13]$} \\
\hline Tetrachlorohydroquinone dehalogenase & $\mathrm{EC}=2.5 .1-$ & Reductive & $\begin{array}{l}\text { Converts tetrachlorohydroquinone to } \\
\text { 2,6-dichlorohydroquinone via } \\
\text { trichlorohydroquinone }\end{array}$ & {$[14]$} \\
\hline $\begin{array}{l}\text { 2,5-Dichlorohydroquinone reductive } \\
\text { dehalogenase }\end{array}$ & $\mathrm{EC}=2.5 .1-$ & Reductive & $\begin{array}{l}\text { Converts 2,5-dichlorohydroquinone to } \\
\text { chlorohydroquinone (CHQ) }\end{array}$ & {$[15]$} \\
\hline Chlorohydroquinone dehalogenase & $\mathrm{EC}=1.97 .1 .-$ & Reductive & $\begin{array}{l}\text { Dehalogenates 2-chlorohydroquinone to } \\
\text { hydroquinone, involved in the degradation } \\
\text { pathway of 2-chloro-4-nitrophenol and } \\
4 \text {-amino-2-chlorophenol }\end{array}$ & {$[16,17]$} \\
\hline 4-Chloro-2-aminophenol dehalogenase & $\mathrm{EC}=1.97 .1 .-$ & Reductive & $\begin{array}{l}\text { Dehalogenates 4-chloro-2-aminophenol to } \\
\text { aminophenol }\end{array}$ & {$[18]$} \\
\hline Pentachlorophenol 4-monooxygenase & $\mathrm{EC}=1.14 .13 .50$ & $\begin{array}{l}\text { Monooxygenase } \\
\text { type }\end{array}$ & $\begin{array}{l}\text { Converts pentachlorophenol to } \\
\text { tetrachlorohydroquinone }\end{array}$ & {$[45]$} \\
\hline Chlorophenol 4-monooxygenase & $\mathrm{EC}=1.14 .13 .-$ & $\begin{array}{l}\text { Monooxygenase } \\
\text { type }\end{array}$ & $\begin{array}{l}\text { Converts 2,4,5-trichlorophenol to } \\
\text { 2,5-dichloro-p-hydroquinone }\end{array}$ & {$[53]$} \\
\hline 2,4,6-Trichlorophenol monooxygenase & $\mathrm{EC}=1.14 .13 .-$ & $\begin{array}{c}\text { Monooxygenase } \\
\text { type }\end{array}$ & $\begin{array}{l}\text { Converts 2,4,6-TCP to } \\
\text { 2-chlorohydroxyquinone via } \\
\text { 2,6-dichloroquinone }\end{array}$ & {$[56]$} \\
\hline 4-Chlorophenylacetate dioxygenase & $\mathrm{EC}=1.14 .12 .9$ & Dioxygenase type & $\begin{array}{l}\text { Converts 4-chlorophenylacetate to } \\
\text { 3,4-dihydroxyphenylacetate }\end{array}$ & {$[60]$} \\
\hline 2-Halobenzoate dioxygenase & $\mathrm{EC}=1.14 .12 .13$ & Dioxygenase type & Converts 2-halobenzoate to catechol & {$[62]$} \\
\hline Chlorobenzene dioxygenase (Tec A) & $\mathrm{EC}=1.14 .12 .-$ & Dioxygenase type & $\begin{array}{l}\text { Converts 1,2,4,5-tetrachlorobenzene to a } \\
\text { 3,4,6-trichlorocatechol }\end{array}$ & {$[68]$} \\
\hline
\end{tabular}

dehalogenase that catalyzes the conversion of 4-chlorobenzoyl-CoA to 4-hydroxybenzoyl-CoA with the release of a chloride ion (Figure 1(a)) [20]. This enzyme is involved in 4-chlorobenzoate degradation and found in several 4chlorobenzoate degrading bacteria, including Burkholderia sp. CBS3 (previously known as Pseudomonas sp. CBS3), Arthrobacter sp. 4-CB1, and Arthrobacter sp. strain TM-1 $[10,20,21]$.

The catalytic mechanism of 4-chlorobenzoyl dehalogenase proceeds by the formation of an aryl-enzyme covalent intermediate via nucleophilic aromatic substitution (Figure 1(b)) [22]. The first step in the hydrolytic dehalogenation involves binding of the enolate anion of the thioester link of 4-chlorobenzoyl-CoA with 4-chlorobenzoyl-CoA dehalogenase to form an enzyme substrate complex, which induces a partially positive charge on the chlorine bearing carbon atom to make it susceptible to nucleophilic attack by aspartate
(Asp145) $[23,24]$. In the second step, Asp145 attacks the C(4)position of the benzoyl ring in the enzyme substrate complex to form Meisenheimer intermediate (or $\sigma$-complex), which then releases chloride to form an aryl-enzyme intermediate [25]. Finally, the aryl-enzyme intermediate is hydrolyzed by a histidine (His90)-bound water molecule to form a tetrahedral intermediate, which decomposes to 4-hydroxybenzoyl-CoA and free enzyme [25].

Crystallographic investigation revealed that the 4-chlorobenzoyl-CoA dehalogenase from strain CBS3 was a homotrimer and that each subunit folded into two motifs $[23,26]$. The N-terminal domain is characterized by 10 strands of beta-pleated sheet that form two nearly perpendicular layers flanked by alpha helices [23]. The C-terminal domain involves trimerization of the protein and contains three amphiphilic alpha helices [23]. The N-terminal domain of the subunit is linked with the C-terminal domain of another subunit 


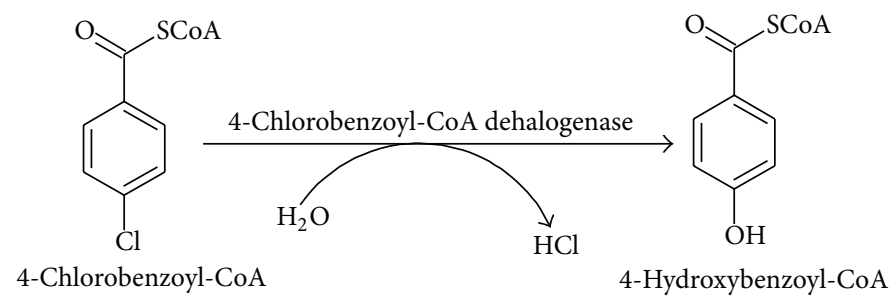

(a)

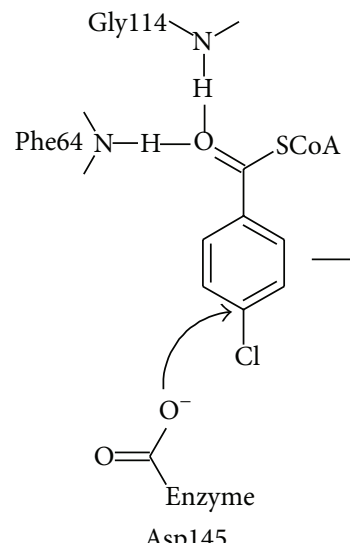

Asp145

Enzyme substrate complex<smiles>CN(C)[IH][OH+]C=[Se]O</smiles><smiles>CC[CH][CH][O+]=C([Se]C(=O)OCc1ccccc1)c1ccc(OC(=O)CCC)cc1</smiles>

Asp145

Asp145

Meisenheimer intermediate

Aryl-enzyme intermediate 
point $(p I)$ of 6.1, while it has a molecular weight of $131 \mathrm{kD}$ with an optimum $\mathrm{pH}$ of 8.0 and a $p I$ of 6.42 in strain TM$1[10,27]$. The N-terminal sequence of the 4-chlorobenzoylCoA dehalogenase from strain 4 -CB1 shows 30\% identity with that from Burkholderia sp. CBS3 and differs from strain TM1 by the presence of additional alanine and valine [27].

1.2. Chlorothalonil Hydrolytic Dehalogenase (Chd). This enzyme was first characterized from Pseudomonas sp. CTN-3 and it is involved in the hydrolytic dehalogenation of chlorothalonil at the para-position with respect to the cyano group (Figure 1(c)). Chd catalyzes the conversion of 2,4,5,6-tetrachloroisophthalonitrile (chlorothalonil) to 4hydroxy-trichloroisophthalonitrile without the requirement of any cofactors [12]. There is no effect of the presence or absence of oxygen on the reaction [12]. The Chd enzyme belongs to the metallo- $\beta$-lactamase superfamily and exhibits 24 to $29 \%$ identity with metallohydrolases [12]. The enzyme has a monomer protein of $36 \mathrm{kD}$ with a $p I$ of 4.13 , a dissociation constant $\left(K_{m}\right)$ of $0.112 \mathrm{mM}$, and an average catalytic rate $\left(k_{\text {cat }}\right)$ of $207 \mathrm{~s}^{-1}$ for chlorothalonil. Site-directed mutagenesis of the chd gene revealed that His128, His157, Ser126, Asp45, Asp130, Asp184, and Trp241 were important to maintain the dehalogenase activity [12]. Chd differs from 4-chlorobenzoyl-CoA dehalogenase due to its amino acid sequences and catalytic properties [12]. Furthermore, there were no conserved catalytic residues between 4chlorobenzoyl-CoA dehalogenase and Chd [12]. Liang et al. [28] detected the chd gene in sixteen chlorothalonildechlorinating strains belonging to eight different genera, Ochrobactrum, Shinella, Caulobacter, Rhizobium, Bordetella, Pseudoxanthomonas, Pseudomonas, and Lysobacter. The chd genes detected in the sixteen strains were highly similar $(99.4 \%$ to $100 \%)$ to each other and closely associated with a novel insertion sequence, ISOcspl. The promoter of chd gene was located immediately downstream of the right inverted repeat of ISOcsp1, and the sequences between the ISOcsp1 and chd gene were also conserved. These observations strongly suggest that horizontal gene transfer was responsible for widespread distribution of the chd gene in these sixteen strains [28]. Further analysis using toxicity experiments revealed the ecological role of the horizontal transfer of the chd gene [29]. Horizontal gene transfer of chd facilitates bacterial adaptation to chlorothalonil-contaminated sites through biotransformation of chlorothalonil to less toxic 2,4,5-trichloro-6-hydroxybenzene-1,3-dicarbonitrile [29]. In another study, the chd gene was cloned from a chlorothalonildegrading strain, Ochrobactrum lupine TP-D1, which showed 98.4\% similarity with that of Pseudomonas sp. CTN-3 [30]. This gene was closely associated with the insertion element IS-Olup. This conserved sequence containing the chd gene and IS-Olup was also reported in seven degrading strains belonging to five genera, Pseudomonas sp., Achromobacter sp., Ochrobactrum sp., Ralstonia sp., and Lysobacter sp. [31]. The occurrence of the chd and IS-Olup in seven other degrading strains suggests horizontal gene transfer of the chd gene [31]. Further evidence of horizontal transfer of the chd gene by IS-Olup was found by inserting the IS-Olup containing chd gene into the chromosome of Escherichia coli DH10B [31].

1.3. Tetrachlorohydroquinone Reductive Dehalogenase (PcpC). $\mathrm{PcpC}$ is a crucial enzyme of the degradation pathway of pentachlorophenol (PCP) that has been well-studied in the PCP-degrading aerobic bacterium, Sphingobium chlorophenolicum L-1 (previously known as strain ATCC 39723) [14]. This enzyme belongs to the glutathione-S-transferase (GST) superfamily and catalyzes sequential dehalogenation of tetrachlorohydroquinone (TeCHQ) to 2,6-dichlorohydroquinone (DCHQ) via 2,3,6-trichlorohydroquinone (TCHQ) (Figure 2(a)) [14]. Each dehalogenation step requires two molecules of glutathione [14].

PcpC has sequence identity (but not more than 25\%) with members of the zeta classes of the GST superfamily [32]. The enzymes in the GST superfamily generally form glutathione conjugates via nucleophilic attack of glutathione upon an electrophilic substrate [32]. A few enzymes of the GST family, including $\mathrm{PcpC}$, maleylacetoacetate isomerase, and maleylpyruvate isomerase, have complex and unusual mechanisms involving additional steps before and/or after the nucleophilic attack of glutathione on an electrophilic intermediate [32-36]. It has been suggested that PcpC originated from a maleylacetoacetate (MAA) isomerase or maleylpyruvate $(\mathrm{MP})$ isomerase because it catalyzes isomerization of MAA and MP and its active site is highly conserved [32].

Cys13 at the active site of $\mathrm{PcpC}$ is required for dehalogenation of TCHQ to TriCHQ, as well as TriCHQ to DCHQ $[33,37]$. In such a case, when cysteine 13 is oxidatively damaged, the damaged enzyme yields S-glutathionyl-TriCH (GS-TriCH) and GS-DiCH conjugates as products [38]. The oxidative damage of PcpC may be removed by treatment with dithiothreitol (DTT), indicating that this damage may involve a cysteine residue [38].

Habash et al. [39] carried out mutational studies in the $\mathrm{N}$-terminal residues (serine and cysteine) of the PcpC in Sphingomonas sp. UG30 and observed functional and structural changes. UG30 PcpC showed 94\% identity with PcpC from Sphingobium chlorophenolicum L-1, with differences being observed in their functional and kinetic properties. Additionally, the optimum temperature and $\mathrm{pH}$ of UG30 PcpC were higher than that of $S$. chlorophenolicum PcpC. S. chlorophenolicum PcpC was inhibited by TCHQ, whereas the UG30 PcpC was not inhibited by the substrate $[39,40]$.

\subsection{2,5-Dichlorohydroquinone Reductive Dehalogenase} (LinD). LinD is a glutathione-dependent reductive dehalogenase involved in the degradation of gamma-hexachlorocyclohexane by Sphingobium japonicum UT-26 [15]. This enzyme catalyzes the conversion of 2,5-dichlorohydroquinone to 2-chlorohydroquinone (CHQ) and slowly converts CHQ to hydroquinone (Figure 2(b)) [15]. LinD is a member of the GST family but is only $25 \%$ homologous with PcpC. The residues in the active sites of LinD and some maleylpyruvate isomerases are conserved, suggesting that LinD may have evolved from other members of the GST family [32]. This enzyme is encoded by the $\operatorname{lin} D$ gene and 


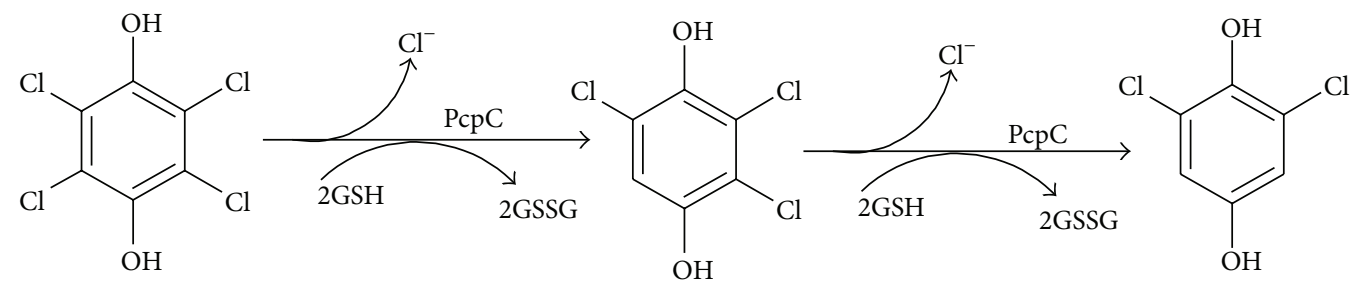

(a)<smiles>Oc1cc(Cl)c(O)cc1Cl</smiles><smiles>Oc1ccc(O)c(Cl)c1</smiles><smiles>CC(C)Cl</smiles><smiles>Oc1ccc(O)cc1</smiles>

(b)

Figure 2: Reductive dehalogenation of (a) tetrachlorohydroquinone by a tetrachlorohydroquinone dehalogenase (PcpC) and (b) 2,5dichlorohydroquinone by a 2,5-dichlorohydroquinone dehalogenase (LinD).

consists of a peptide of 343 amino acids [15]. Comparison of the genome of UT-26 with those of Sphingomonas sp. SKA58, Sphingobium sp. SYK-6, Sphingomonas wittichii RW1, Sphingopyxis alaskensis RB2256, and Novosphingobium aromaticivorans DSM 12444 revealed that lin genes including linD are located on unique regions of strain UT-26 and are closely associated with insertion sequence IS6100, suggesting an important role of IS6100 in the distribution of specific lin genes [41-44].

1.5. Pentachlorophenol-4-Monooxygenase (PcpB). РcpB, which is the first enzyme of the degradation pathway of pentachlorophenol (PCP) in Sphingobium chlorophenolicum L-1, converts PCP to TeCHQ with oxidative removal of the chloride ion (Figure 3(a)) [45]. This enzyme requires one molecule of oxygen and two molecules of NADPH for reaction [45]. PcpB catalyzes hydroxylation of the para position of a wide range of polyhalogenated phenols including 2,3,5,6-tetrachlorophenol, 2,4,6-triiodophenol, 2,4,6-tribromophenol, and 2,6-dichlorophenol [46]. PcpB is encoded by the $p c p B$ gene in Sphingobium chlorophenolicum L-1, which has been identified in a variety of PCPdegrading and non-PCP degrading bacteria isolated from PCP-contaminated sites [9, 47]. The occurrence of the $p c p B$ gene in a number of bacteria isolated from PCPcontaminated environments suggests the involvement of natural horizontal transfer of the gene [48]. The homologous enzymes from Novosphingobium lentum MT1 [49], several polychlorophenol-degrading Sphingomonads from Finland [48], Sphingomonas sp. UG30 [50], and those of several uncultured bacteria from environmental samples collected from PCP-contaminated soils [51] showed 72-98\% identity with $\mathrm{PcpB}$.

1.6. Chlorophenol-4-Monooxygenase. This enzyme converts 2,4,5-trichlorophenol to 2,5-dichloro-p-hydroquinone with the release of chloride ions in the degradation pathway of 2,4,5-trichlorophenoxyacetic acid by Burkholderia cepacia AC1100 (Figure 3(b)) [52]. The gene ( $t f t D)$ encoding chlorophenol monooxygenase (TftD) has been characterized from B. cepacia AC1100 [52-55]. This enzyme has a molecular weight of $22 \mathrm{kD}$ and requires $\mathrm{O}_{2}, \mathrm{FAD}$, and $\mathrm{NADH}$ to catalyze the reaction.

1.7. 2,4,6-Trichlorophenol Monooxygenase. This enzyme was characterized in Azotobacter sp. GP1 and Cupriavidus necator JMP134 (previously known as Ralstonia eutropha) JMP134 $[56,57]$. The 2,4,6-trichlorophenol-4-monooxygenase from Azotobacter sp. GP1 converts 2,4,6-trichlorophenol (TCP) to 2,6-dichlorohydroquinone with the release of a chloride ion (Figure 3(c)) [57]. This enzymeis a homotetrameric protein with a molecular weight of $240 \mathrm{kD}$ and a subunit weight of $60 \mathrm{kD}$ that requires $\mathrm{NADH}$, flavin adenine dinucleotide, and $\mathrm{O}_{2}$ as cofactors [57]. Another 2,4,6-trichlorophenol-4monooxygenase from Cupriavidus necator JMP134 converted 2,4,6-TCP to 2-chlorohydroxyquinone via sequential dehalogenation [56]. This monooxygenase is a monomeric protein of $60 \mathrm{kDa}$ that converts $2,4,6$-TCP to 2,6 -dichloroquinone and finally to 2-chlorohydroxyquinone, which is reduced to 6-chlorohydroxyquinol and requires molecular oxygen, $\mathrm{NADH}, \mathrm{FAD}$, and riboflavin reductase $[\mathrm{NAD}(\mathrm{P}) \mathrm{H}] / \mathrm{FMN}$ reductase for activity [56]. The gene (tcpA) encoding this 


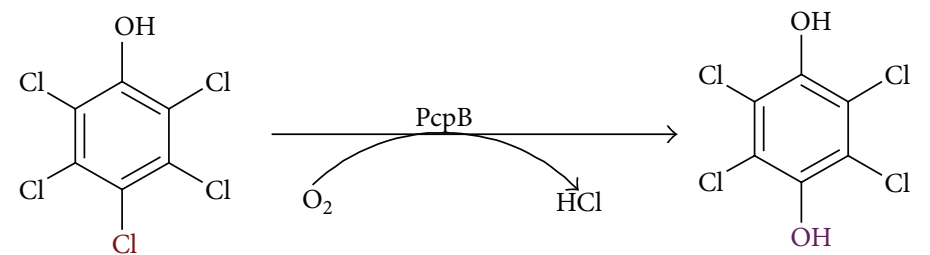

Pentachlorophenol

Tetrachlorohydroquinone

(a)<smiles>Oc1cc(Cl)c(Cl)cc1Cl</smiles>

2,4,5-Trichlorophenol

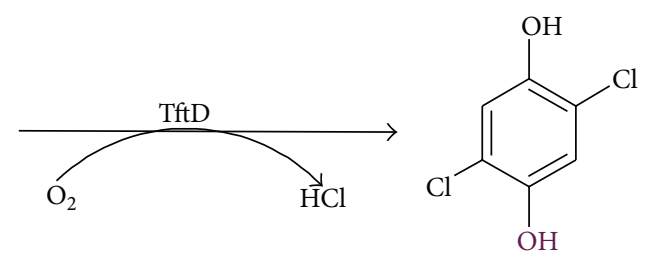

2,5-Dichloro-p-hydroquinone

(b)

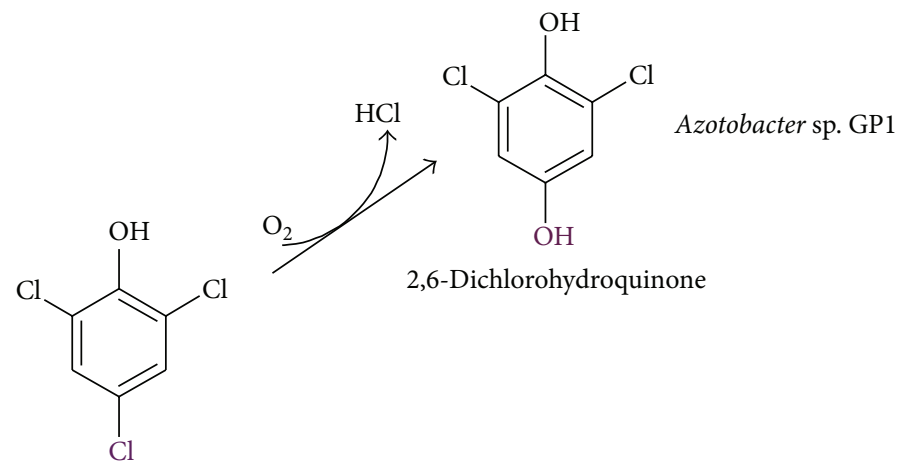

2,4,6-Trichlorophenol

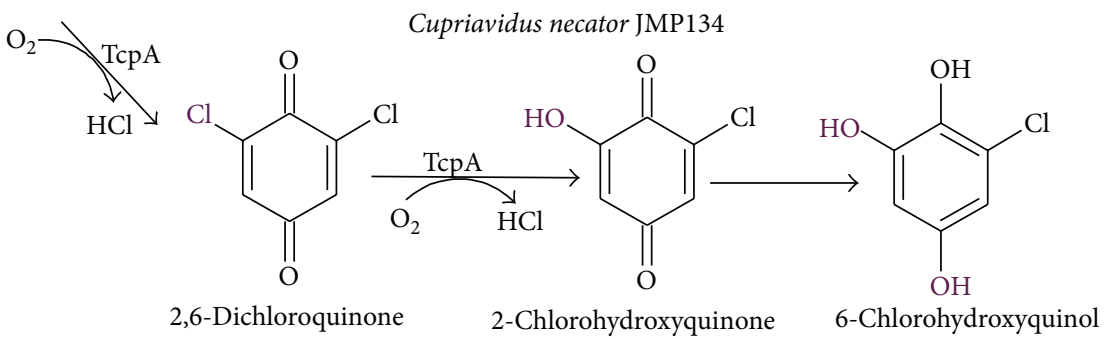

(c)

FIGURE 3: Monooxygenase type dehalogenation of (a) pentachlorophenol by pentachlorophenol-4-monooxygenase (PcpB); (b) 2,4,5trichlorophenol by chlorophenol monooxygenase (TftD) and (c) 2,4,6-trichlorophenol by 2,4,6-trichlorophenol monooxygenase.

enzyme (TcpA) has been identified and characterized in Cupriavidus necator JMP134 [58, 59].

1.8. 4-Chlorophenylacetate-3,4-Dioxygenase. This enzyme catalyzes the conversion of 4-chlorophenylacetate to 3,4 dihydroxyphenylacetate and requires $\mathrm{NADH}$ and $\mathrm{Fe}^{2+}$ as cofactors (Figure 4(a)) [60,61]. This enzyme has been studied in Burkholderia sp. CBS3, which utilizes 2-chloroacetate, 4-chlorobenzoate, and 4-chlorophenyl acetate as the sole carbon and energy sources. 4-Chlorophenylacetate-3,4dioxygenase is composed of two components, in which the large component (A) is an iron-sulfur protein that acts as a dioxygenase, and the small component (B) acts as a reductase $[60,61]$. Component $A$ is a trimetric protein with a molecular weight of $140 \mathrm{kD}[60]$ that is composed of three subunits with a molecular range of $46 \mathrm{kD}$ to $52 \mathrm{kD}$, whereas component $\mathrm{B}$ is a monomer protein with molecular weight of $35 \mathrm{kD}$ that has a [2Fe-2S] type iron-sulfur cluster [61].

1.9. 2-Halobenzoate-1,2-Dioxygenase. This enzyme, which was first studied in Burkholderia sp. 2CBS, converts 2chlorobenzoate, 2-fluorobenzoate, 2-bromobenzoate, and 2iodobenzoate to catechol with concomitant release of carbon dioxide and halides (Figure 4(b)) $[62,63]$ and requires 
<smiles>CC(=O)Oc1ccc(Cl)cc1</smiles>
4-Chlorophenylacetate
3,4-Dihydroxyphenylacetate<smiles>O=C(O)c1ccccc1Cl</smiles>

2-Chlorobenzoate<smiles>CC1C(=O)C2CCC(=O)C1C2Cl</smiles>

Catechol

(a)

(b)<smiles>CC(=O)C1C(C)C(=O)C1C</smiles><smiles>Oc1c(Cl)cc(Cl)c(Cl)c1O</smiles>

1,2,4,5-Tetrachlorobenzene

3,4,6-Trichlorocatechol

(c)

FIGURE 4: Dioxygenase type dehalogenation of (a) 4-chlorophenylacetate by 4-chlorophenylacetate-3,4-dioxygenase; (b) 2-chlorobenzoate by a halobenzoate dehalogenase and (c) 1,2,4,5-tetrachlorobenzene by a chlorobenzene dioxygenase.

$\mathrm{NADH}$ and $\mathrm{Fe}^{2+}$ as cofactors. The gene cluster encoding this enzyme, $c b d A B C$, is located on the $70-\mathrm{kb}$ plasmid pBAH1 in strain 2CBS [63]. The enzyme from strain 2CBS is a twocomponent protein consisting of a dioxygenase and an electron transfer component [63]. The dioxygenase is composed of $3 \alpha$ - and $3 \beta$-subunits encoded by the genes $\operatorname{chd} \mathrm{A}$ and $\operatorname{ch} d \mathrm{~B}$, respectively [63]. Each $\alpha$-subunit has a molecular weight of $52 \mathrm{kD}$, while each $\beta$-subunit has a molecular weight of $20 \mathrm{kD}$. The electron transfer component is a monomeric protein of $37 \mathrm{kD}$ that is encoded by the gene $c b d C$ and has NADHacceptor reductase activity [63]. Suzuki et al. [64] cloned and sequenced the $c b d A B C$ genes from Burkholderia sp. TH2 and found predicted amino acid sequences highly similar to the $c b d$ gene products of strain 2CBS. The halobenzoate-1,2dioxygenase is similar to benzoate dioxygenases but differs from a three-component dioxygenase from Pseudomonas aeruginosa strain 14 , which catalyzes ortho-dehalogenation of 2-chlorobenzoate and 2,4-dichlorobenzoate [65].

1.10. Chlorobenzene Dioxygenase (TecA). The chlorobenzene dioxygenase (TecA) of Burkholderia sp. strain PS12 dechlorinates 1,2,4,5-tetrachlorobenzene to 3,4,6-trichlorocatechol (Figure 4(c)) [66, 67]. The gene (tecA) encoding this enzyme (TecA) was located in the plasmid [67]. This enzyme belongs to the Class IIB dioxygenases, which are composed of a terminal dioxygenase, a reductase (TecA3), and a ferredoxin (TecA4). The dioxygenase is composed of a large $\alpha$-subunit (TecA1) and a small $\beta$-subunit (TecA2) with an $(\alpha \beta)_{n}$ configuration [66]. The large $\alpha$-subunit of TecA determines the substrate specificity of the enzyme and contains a Rieske (2Fe2S) centre and a mononuclear nonhaem iron [68].

\section{Conclusions and Future Perspectives}

(i) Bacterial aromatic dehalogenases play an important role in dehalogenation of chlorinated aromatic compounds, which is a crucial step in the degradation of these compounds. To date, many hydrolytic, reductive, and oxygenolytic aromatic dehalogenases have been identified; however, detailed mechanistic studies have only been conducted for a few.

(ii) 4-Chlorobenzoyl-CoA dehalogenase is a well-characterized hydrolytic dehalogenase and its catalytic mechanism has also been studied. Furthermore, the crystal structure of this dehalogenase provided detailed insight into the hydrolytic dehalogenation of chlorinated aromatic compounds.

(iii) Chlorothalonil hydrolytic dehalogenase is a newly characterized hydrolytic dehalogenase. More efforts are needed to understand its catalytic mechanism. The crystal structure of this dehalogenase should be investigated to understand the dehalogenation of chlorothalonil.

(iv) Tetrachlorohydroquinone reductive dehalogenase $(\mathrm{PcpC})$ is the only aromatic reductive dehalogenase whose mechanism has been studied in detail. Similar studies should be carried out for other reductive aromatic dehalogenases such as LinD.

(v) Pentachlorophenol-4-monooxygenase is the most important monooxygenase type dehalogenase. The genetics of this dehalogenase has been studied and the gene coding this enzyme ( $p c p \mathrm{~B})$ has been identified in a variety of bacteria. The crystal structure of 
this dehalogenase may provide new insights into oxygenolytic dehalogenation of pentachlorophenol.

(vi) The genetics and biochemical studies of dioxygenase type dehalogenases have been carried out. Further development can be done to improve the efficiency of these dehalogenases.

(vii) The biocatalytic applications of the aromatic dehalogenases may be improved using the current approaches of genomics and proteomics. Metagenomic approach can be used to find out new dehalogenases from various environmental samples. Furthermore, the catalytic properties of dehalogenases can be enhanced by protein engineering. Directed evolution can be used to construct the engineered dehalogenases to improve their efficiency.

(viii) Future studies on the biochemical and molecular characterization of aromatic dehalogenases will increase our understanding of this class of enzymes.

\section{Conflict of Interests}

The authors declare that they have no competing interests.

\section{Authors' Contribution}

Pankaj Kumar Arora collected all the relevant publications, arranged the general structure of the review, drafted the text, and produced figures. Hanhong Bae revised the paper. All authors read and approved the final paper.

\section{Acknowledgment}

This work was carried out with the support of "Cooperative Research Program for Agriculture Science \& Technology Development (PJ01049704)" Rural Development Administration, Republic of Korea.

\section{References}

[1] P. K. Arora and H. Bae, "Bacterial degradation of chlorophenols and their derivatives," Microbial Cell Factories, vol. 13, no. 1, article 31, 2014.

[2] S. R. Sahasrabudhe and V. V. Modi, "Microbial degradation of chlorinated aromatic compounds," Microbiological Sciences, vol. 4, no. 10, pp. 300-303, 1987.

[3] S. D. Copley, "Diverse mechanistic approaches to difficult chemical transformations: microbial dehalogenation of chlorinated aromatic compounds," Chemistry \& Biology, vol. 4, no. 3, pp. 169-174, 1997.

[4] P. K. Arora, C. Sasikala, and C. V. Ramana, "Degradation of chlorinated nitroaromatic compounds," Applied Microbiology and Biotechnology, vol. 93, no. 6, pp. 2265-2277, 2012.

[5] M. Kunze, K. F. Zerlin, A. Retzlaff et al., "Degradation of chloroaromatics by Pseudomonas putida GJ31: assembled route for chlorobenzene degradation encoded by clusters on plasmid pKW1 and the chromosome," Microbiology, vol. 155, no. 12, pp. 4069-4083, 2009.
[6] P. K. Donnelly, J. A. Entry, and D. L. Crawford, "Degradation of atrazine and 2,4-dichlorophenoxyacetic acid by mycorrhizal fungi at three nitrogen concentrations in vitro," Applied and Environmental Microbiology, vol. 59, no. 8, pp. 2642-2647, 1993.

[7] P. K. Arora, A. Srivastava, and V. P. Singh, "Bacterial degradation of nitrophenols and their derivatives," Journal of Hazardous Materials, vol. 266, pp. 42-59, 2014.

[8] S. Fetzner and F. Lingens, "Bacterial dehalogenases: biochemistry, genetics, and biotechnological applications," Microbiological Reviews, vol. 58, no. 4, pp. 641-685, 1994.

[9] P. K. Arora, A. Srivastava, and V. P. Singh, "Application of monooxygenases in dehalogenation, desulphurization, denitrification and hydroxylation of aromatic compounds," Journal of Bioremediation and Biodegradation, vol. 1, p. 112, 2010.

[10] G. P. Crooks, "Purification and characterization of 4-chlorobenzoyl CoA dehalogenase from arthrobacter sp. strain 4-cbl," Biochemistry, vol. 33, no. 38, pp. 11645-11649, 1994.

[11] L. A. Heppel and V. T. Porterfield, "Enzymatic dehalogenation of certain brominated and chlorinated compounds," Journal of Biological Chemistry, vol. 176, pp. 763-769, 1948.

[12] G. Wang, R. Li, S. Li, and J. Jiang, "A novel hydrolytic dehalogenase for the chlorinated aromatic compound chlorothalonil," Journal of Bacteriology, vol. 192, no. 11, pp. 2737-2745, 2010.

[13] M. L. de Souza, M. J. Sadowsky, and L. P. Wackett, "Atrazine chlorohydrolase from Pseudomonas sp. strain ADP: gene sequence, enzyme purification, and protein characterization," Journal of Bacteriology, vol. 178, no. 16, pp. 4894-4900, 1996.

[14] L. Xun, E. Topp, and C. S. Orser, "Purification and characterization of a tetrachloro- $p$-hydroquinone reductive dehalogenase from a Flavobacterium sp," Journal of Bacteriology, vol. 174, no. 24, pp. 8003-8007, 1992.

[15] K. Miyauchi, S.-K. Suh, Y. Nagata, and M. Takagi, "Cloning and sequencing of a 2,5-dichlorohydroquinone reductive dehalogenase gene whose product is involved in degradation of $\gamma$ hexachlorocyclohexane by Sphingomonas paucimobilis," Journal of Bacteriology, vol. 180, no. 6, pp. 1354-1359, 1998.

[16] P. K. Arora and R. K. Jain, "Metabolism of 2-chloro-4nitrophenol in a gram negative bacterium, Burkholderia sp. RKJ 800," PLoS ONE, vol. 7, no. 6, Article ID e38676, 2012.

[17] P. K. Arora, A. Srivastava, and V. Singh, "Novel degradation pathway of 2-chloro-4-aminophenol in Arthrobacter sp. SPG," PeerJ PrePrints, vol. 2, p. e194vl, 2014.

[18] P. K. Arora, A. Sharma, R. Mehta, B. D. Shenoy, A. Srivastava, and V. P. Singh, "Metabolism of 4-chloro-2-nitrophenol in a Gram-positive bacterium, Exiguobacterium sp. PMA," Microbial Cell Factories, vol. 11, article 150, 2012.

[19] K. Miyauchi, Y. Adachi, Y. Nagata, and M. Takagi, "Cloning and sequencing of a novel meta-cleavage dioxygenase gene whose product is involved in degradation of $\gamma$-hexachlorocyclohexane in Sphingomonas paucimobilis," Journal of Bacteriology, vol. 181, no. 21, pp. 6712-6719, 1999.

[20] F. Löffler, F. Lingens, and R. Müller, "Dehalogenation of 4-chlorobenzoate. Characterisation of 4-chlorobenzoyl-coenzyme A dehalogenase from Pseudomonas sp. CBS3," Biodegradation, vol. 6, no. 3, pp. 203-212, 1995.

[21] L. Zhou, R. P. C. Poh, T. S. Marks, B. Z. Chowdhry, and A. R. W. Smith, "Structure and denaturation of 4-chlorobenzoyl coenzyme A dehalogenase from Arthrobacter sp. strain TM-1," Biodegradation, vol. 19, no. 1, pp. 65-75, 2008.

[22] G. P. Crooks, L. Xu, R. M. Barkley, and S. D. Copley, "Exploration of possible mechanisms for 4-chlorobenzoyl CoA 
dehalogenase: evidence for an aryl-enzyme intermediate," Journal of the American Chemical Society, vol. 117, no. 44, pp. 1079110798, 1995.

[23] R. M. de Jong and B. W. Dijkstra, "Structure and mechanism of bacterial dehalogenases: different ways to cleave a carbonhalogen bond," Current Opinion in Structural Biology, vol. 13, no. 6, pp. 722-730, 2003.

[24] E. Y. Lau and T. C. Bruice, "The active site dynamics of 4chlorobenzoyl-CoA dehalogenase," Proceedings of the National Academy of Sciences of the United States of America, vol. 98, no. 17, pp. 9527-9532, 2001.

[25] L. S. Luo, K. L. Taylor, H. Xiang, Y. Wei, W. Zhang, and D. Dunaway-Mariano, "Role of active site binding interactions in 4-chlorobenzoyl-coenzyme A dehalogenase catalysis," Biochemistry, vol. 40, no. 51, pp. 15684-15692, 2001.

[26] M. M. Benning, K. L. Taylor, R.-Q. Liu et al., "Structure of 4chlorobenzoyl coenzyme A dehalogenase determined to $1.8 \AA$ resolution: an enzyme catalyst generated via adaptive mutation," Biochemistry, vol. 35, no. 25, pp. 8103-8109, 1996.

[27] L. Zhou, T. S. Marks, R. P. C. Poh, R. J. Smith, B. Z. Chowdhry, and A. R. W. Smith, "The purification and characterisation of 4chlorobenzoate:CoA ligase and 4-chlorobenzoyl CoA dehalogenase from Arthrobacter sp. strain TM-1," Biodegradation, vol. 15, no. 2, pp. 97-109, 2004.

[28] B. Liang, G. Wang, Y. Zhao, K. Chen, S. Li, and J. Jiang, "Facilitation of bacterial adaptation to chlorothalonil-contaminated sites by horizontal transfer of the chlorothalonil hydrolytic dehalogenase gene," Applied and Environmental Microbiology, vol. 77, no. 12, pp. 4268-4272, 2011.

[29] B. Liang, J. Jiang, J. Zhang, Y. Zhao, and S. Li, "Horizontal transfer of dehalogenase genes involved in the catalysis of chlorinated compounds: evidence and ecological role," Critical Reviews in Microbiology, vol. 38, no. 2, pp. 95-102, 2012.

[30] X.-Z. Shi, R.-J. Guo, K. Takagi, Z.-Q. Miao, and S.-D. Li, "Chlorothalonil degradation by Ochrobactrum lupini strain TPD1 and identification of its metabolites," World Journal of Microbiology and Biotechnology, vol. 27, no. 8, pp. 1755-1764, 2011.

[31] G. Wang, B. Liang, F. Li, and S. Li, "Recent advances in the biodegradation of chlorothalonil," Current Microbiology, vol. 63, no. 5, pp. 450-457, 2011.

[32] S. D. Copley, J. Rokicki, P. Turner, H. Daligault, M. Nolan, and M. Land, "The whole genome sequence of Sphingobium chlorophenolicum L-1: insights into the evolution of the pentachlorophenol degradation pathway," Genome Biology and Evolution, vol. 4, no. 2, pp. 184-198, 2012.

[33] J. R. Warner, S. L. Lawson, and S. D. Copley, "A mechanistic investigation of the thiol-disulfide exchange step in the reductive dehalogenation catalyzed by tetrachlorohydroquinone dehalogenase," Biochemistry, vol. 44, no. 30, pp. 1036010368, 2005.

[34] J. R. Warner and S. D. Copley, "Pre-steady-state kinetic studies of the reductive dehalogenation catalyzed by tetrachlorohydroquinone dehalogenase," Biochemistry, vol. 46, no. 45, pp. 1321113222, 2007.

[35] G. Polekhina, P. G. Board, A. C. Blackburn, and M. W. Parker, "Crystal structure of maleylacetoacetate isomerase/glutathione transferase zeta reveals the molecular basis for its remarkable catalytic promiscuity," Biochemistry, vol. 40, no. 6, pp. 15671576, 2001.

[36] M. Marsh, D. K. Shoemark, A. Jacob et al., "Structure of bacterial glutathione-S-transferase maleyl pyruvate isomerase and implications for mechanism of isomerisation," Journal of Molecular Biology, vol. 384, no. 1, pp. 165-177, 2008.

[37] D. L. McCarthy, S. Navarrete, W. S. Willett, P. C. Babbitt, and S. D. Copley, "Exploration of the relationship between tetrachlorohydroquinone dehalogenase and the glutathione $S$ transferase superfamily," Biochemistry, vol. 35, no. 46, pp. 14634-14642, 1996.

[38] D. L. McCarthy, D. F. Louie, and S. D. Copley, "Identification of a covalent intermediate between glutathione and cysteine13 formed during catalysis by tetrachlorohydroquinone dehalogenase," Journal of the American Chemical Society, vol. 119, no. 46, pp. 11337-11338, 1997.

[39] M. Habash, B. C. H. Chu, J. T. Trevors, and H. Lee, "Mutational study of the role of $\mathrm{N}$-terminal amino acid residues in tetrachlorohydroquinone reductive dehalogenase from Sphingomonas sp. UG30," Research in Microbiology, vol. 160, no. 8, pp. 553-559, 2009.

[40] M. B. Habash, L. A. Beaudette, M. B. Cassidy et al., "Characterization of tetrachlorohydroquinone reductive dehalogenase from Sphingomonas sp. UG30," Biochemical and Biophysical Research Communications, vol. 299, no. 4, pp. 634-640, 2002.

[41] E. Masai, Y. Katayama, and M. Fukuda, "Genetic and biochemical investigations on bacterial catabolic pathways for ligninderived aromatic compounds," Bioscience, Biotechnology and Biochemistry, vol. 71, no. 1, pp. 1-15, 2007.

[42] T. R. Miller, A. L. Delcher, S. L. Salzberg, E. Saunders, J. C. Detter, and R. U. Halden, "Genome sequence of the dioxinmineralizing bacterium Sphingomonas wittichii RW1," Journal of Bacteriology, vol. 192, no. 22, pp. 6101-6102, 2010.

[43] F. M. Lauro, D. McDougald, T. Thomas et al., "The genomic basis of trophic strategy in marine bacteria," Proceedings of the National Academy of Sciences of the United States of America, vol. 106, no. 37, pp. 15527-15533, 2009.

[44] Y. Nagata, S. Natsui, R. Endo et al., "Genomic organization and genomic structural rearrangements of Sphingobium japonicum UT26, an archetypal $\gamma$-hexachlorocyclohexane-degrading bacterium," Enzyme and Microbial Technology, vol. 49, no. 6-7, pp. 499-508, 2011.

[45] C. S. Orser, C. C. Lange, L. Xun, T. C. Zahrt, and B. J. Schneider, "Cloning, sequence analysis, and expression of the Flavobacterium pentachlorophenol-4-monooxygenase gene in Escherichia coli," Journal of Bacteriology, vol. 175, no. 2, pp. 411416, 1993.

[46] R. L. Crawford, C. M. Jung, and J. L. Strap, “The recent evolution of pentachlorophenol (PCP)-4-monooxygenase (PcpB) and associated pathways for bacterial degradation of PCP," Biodegradation, vol. 18, no. 5, pp. 525-539, 2007.

[47] V. M. Saboo and M. A. Gealt, "Gene sequences of the pcpB gene of pentachlorophenol-degrading Sphingomonas chlorophenolica found in nondegrading bacteria," Canadian Journal of Microbiology, vol. 44, no. 7, pp. 667-675, 1998.

[48] M. A. Tiirola, H. Wang, L. Paulin, and M. S. Kulomaa, "Evidence for natural horizontal transfer of the $\mathrm{pcpB}$ gene in the evolution of polychlorophenol-degrading sphingomonads," Applied and Environmental Microbiology, vol. 68, no. 9, pp. 4495-4501, 2002.

[49] M. A. Tiirola, M. K. Männistö, J. A. Puhakka, and M. S. Kulomaa, "Isolation and characterization of Novosphingobium sp. strain MT1, a dominant polychlorophenol-degrading strain in a groundwater bioremediation system," Applied and Environmental Microbiology, vol. 68, no. 1, pp. 173-180, 2002.

[50] M. B. Cassidy, H. Lee, J. T. Trevors, and R. B. Zablotowicz, "Chlorophenol and nitrophenol metabolism by Sphingomonas 
sp UG30," Journal of Industrial Microbiology and Biotechnology, vol. 23, no. 4-5, pp. 232-241, 1999.

[51] M. Beaulieu, V. Bécaert, L. Deschênes, and R. Villemur, "Evolution of bacterial diversity during enrichment of PCP-degrading activated soils," Microbial Ecology, vol. 40, no. 4, pp. 345-356, 2000.

[52] G. Martin-Le Garrec, I. Artaud, and C. Capeillère-Blandin, "Purification and catalytic properties of the chlorophenol 4monooxygenase from Burkholderia cepacia strain AC1100," Biochimica et Biophysica Acta, vol. 1547, no. 2, pp. 288-301, 2001.

[53] B. N. Webb, J. W. Ballinger, E. Kim et al., "Characterization of chlorophenol 4-monooxygenase (TfD) and NADH:FAD oxidoreductase (TftC) of Burkholderia cepacia AC1100," The Journal of Biological Chemistry, vol. 285, no. 3, pp. 2014-2027, 2010.

[54] M. R. Gisi and L. Y. Xun, "Characterization of chlorophenol 4monooxygenase (TftD) and NADH:flavin adenine dinucleotide oxidoreductase (TftC) of Burkholderia cepacia AC1100," Journal of Bacteriology, vol. 185, no. 9, pp. 2786-2792, 2003.

[55] L. Xun, "Purification and characterization of chlorophenol 4monooxygenase from Burkholderia cepacia AC1100," Journal of Bacteriology, vol. 178, no. 9, pp. 2645-2649, 1996.

[56] L. Xun and C. M. Webster, "A monooxygenase catalyzes sequential dechlorinations of 2,4,6-trichlorophenol by oxidative and hydrolytic reactions," The Journal of Biological Chemistry, vol. 279, no. 8, pp. 6696-6700, 2004.

[57] M. Wieser, B. Wagner, J. Eberspächer, and F. Lingens, "Purification and characterization of 2,4,6-trichlorophenol-4monooxygenase, a dehalogenating enzyme from Azotobacter sp. strain GP1," Journal of Bacteriology, vol. 179, no. 1, pp. 202208, 1997.

[58] R. P. Hayes, B. N. Webb, A. K. Subramanian et al., "Structural and catalytic differences between two FADH 2-dependent monooxygenases: 2,4,5- TCP 4-monooxygenase (TftD) from Burkholderia cepacia AC1100 and 2,4,6-TCP 4-monooxygenase (TcpA) from Cupriavidus necator JMP134," International Journal of Molecular Sciences, vol. 13, no. 8, pp. 9769-9784, 2012.

[59] T. M. Louie, C. M. Webster, and L. Xun, "Genetic and biochemical characterization of a 2,4,6-trichlorophenol degradation pathway in Ralstonia eutropha JMP134," Journal of Bacteriology, vol. 184, no. 13, pp. 3492-3500, 2002.

[60] A. Markus, D. Krekel, and F. Lingens, "Purification and some properties of component $\mathrm{A}$ of the 4-chlorophenylacetate 3,4dioxygenase from Pseudomonas species strain CBS," The Journal of Biological Chemistry, vol. 261, no. 27, pp. 12883-12888, 1986.

[61] D. Schweizer, A. Markus, M. Seez, H. H. Ruf, and F. Lingens, "Purification and some properties of component B of the 4-chlorophenylacetate 3,4-dioxygenase from Pseudomonas species strain CBS 3," The Journal of Biological Chemistry, vol. 262, no. 19, pp. 9340-9346, 1987.

[62] S. Fetzner, R. Müller, and F. Lingens, "Purification and some properties of 2-halobenzoate 1,2-dioxygenase, a twocomponent enzyme system from Pseudomonas cepacia 2CBS," Journal of Bacteriology, vol. 174, no. 1, pp. 279-290, 1992.

[63] B. Haak, S. Fetzner, and F. Lingens, "Cloning, nucleotide sequence, and expression of the plasmid-encoded genes for the two-component 2-halobenzoate 1,2-dioxygenase from $\mathrm{Pseu}$ domonas cepacia 2CBS," Journal of Bacteriology, vol. 177, no. 3, pp. 667-675, 1995.

[64] K. Suzuki, N. Ogawa, and K. Miyashita, "Expression of 2halobenzoate dioxygenase genes (cbdSABC) involved in the degradation of benzoate and 2-halobenzoate in Burkholderia sp. TH2," Gene, vol. 262, no. 1-2, pp. 137-145, 2001.

[65] V. Romanov and R. P. Hausinger, "Pseudomonas aeruginosa 142 uses a three-component ortho-halobenzoate 1,2- dioxygenase for metabolism of 2,4-dichloro- and 2-chlorobenzoate," Journal of Bacteriology, vol. 176, no. 11, pp. 3368-3374, 1994.

[66] S. Beil, B. Happe, K. N. Timmis, and D. H. Pieper, "Genetic and biochemical characterization of the broad spectrum chlorobenzene dioxygenase from Burkholderia sp. strain PS12dechlorination of 1,2,4,5-tetrachlorobenzene," European Journal of Biochemistry, vol. 247, no. 1, pp. 190-199, 1997.

[67] S. Beil, K. N. Timmis, and D. H. Pieper, "Genetic and biochemical analyses of the tec operon suggest a route for evolution of chlorobenzene degradation genes," Journal of Bacteriology, vol. 181, no. 1, pp. 341-346, 1999.

[68] S. Beil, J. R. Mason, K. N. Timmis, and D. H. Pieper, "Identification of chlorobenzene dioxygenase sequence elements involved in dechlorination of 1,2,4,5-tetrachlorobenzene," Journal of Bacteriology, vol. 180, no. 21, pp. 5520-5528, 1998. 

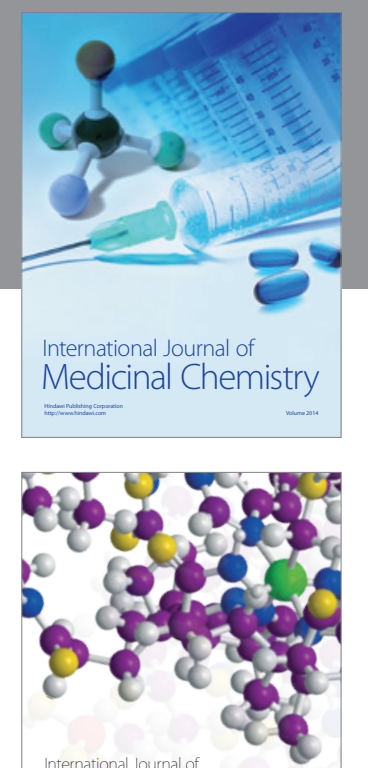

\section{Carbohydrate} Chemistry

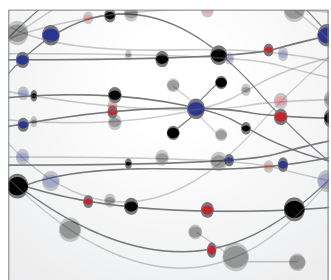

The Scientific World Journal
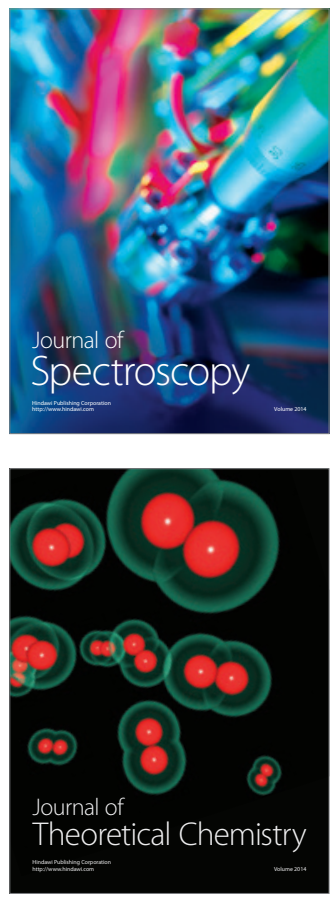
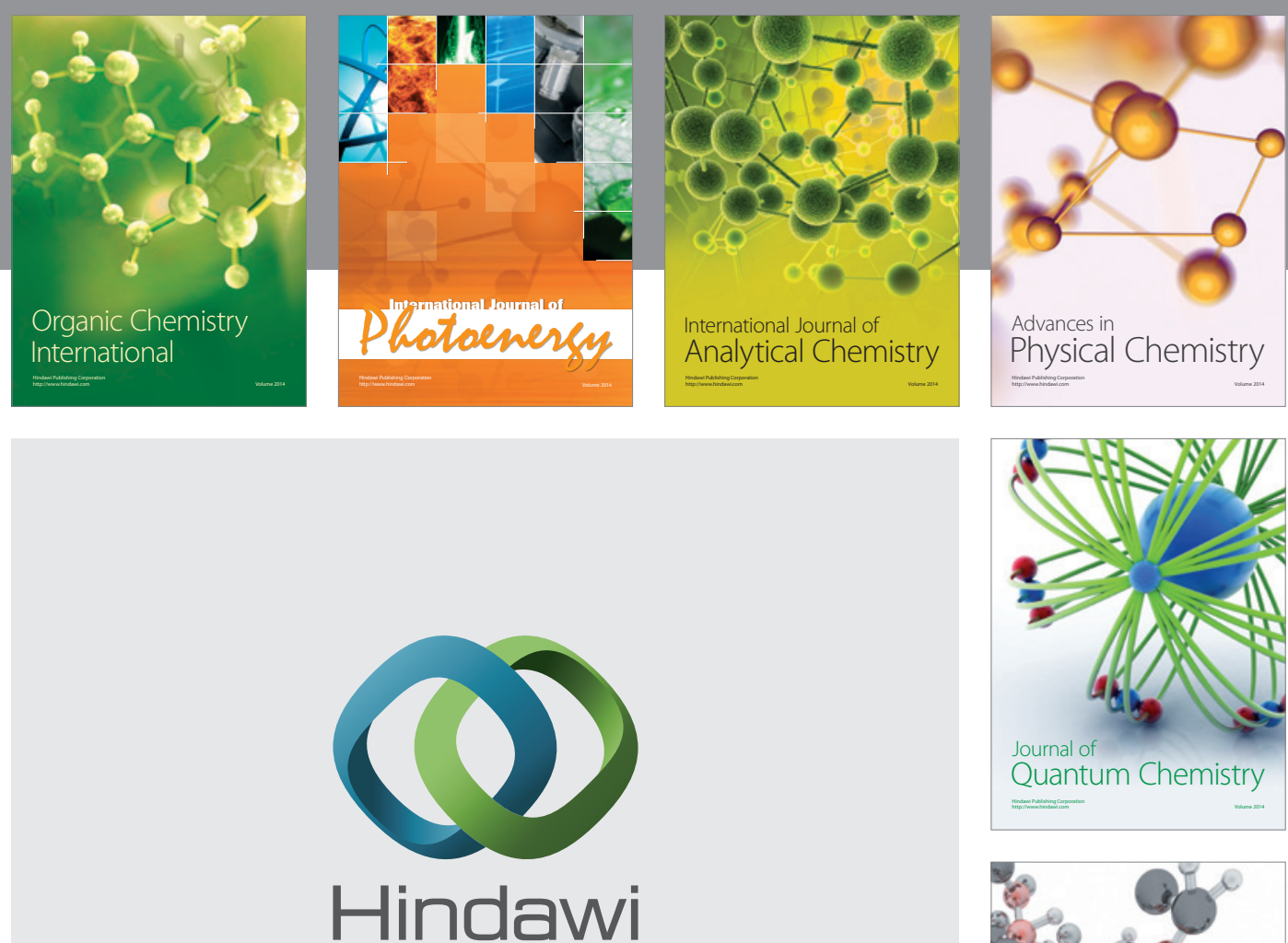

Submit your manuscripts at

http://www.hindawi.com

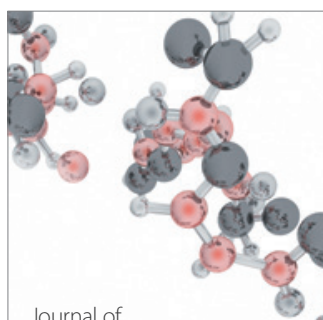

Analytical Methods

in Chemistry

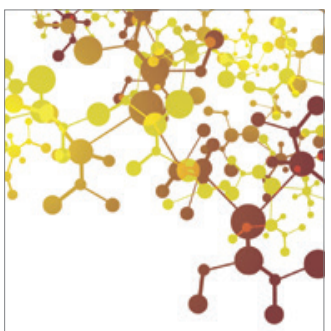

Journal of

Applied Chemistry

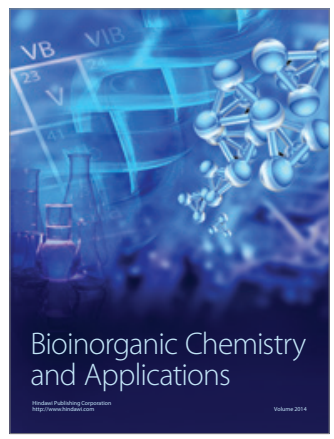

Inorganic Chemistry
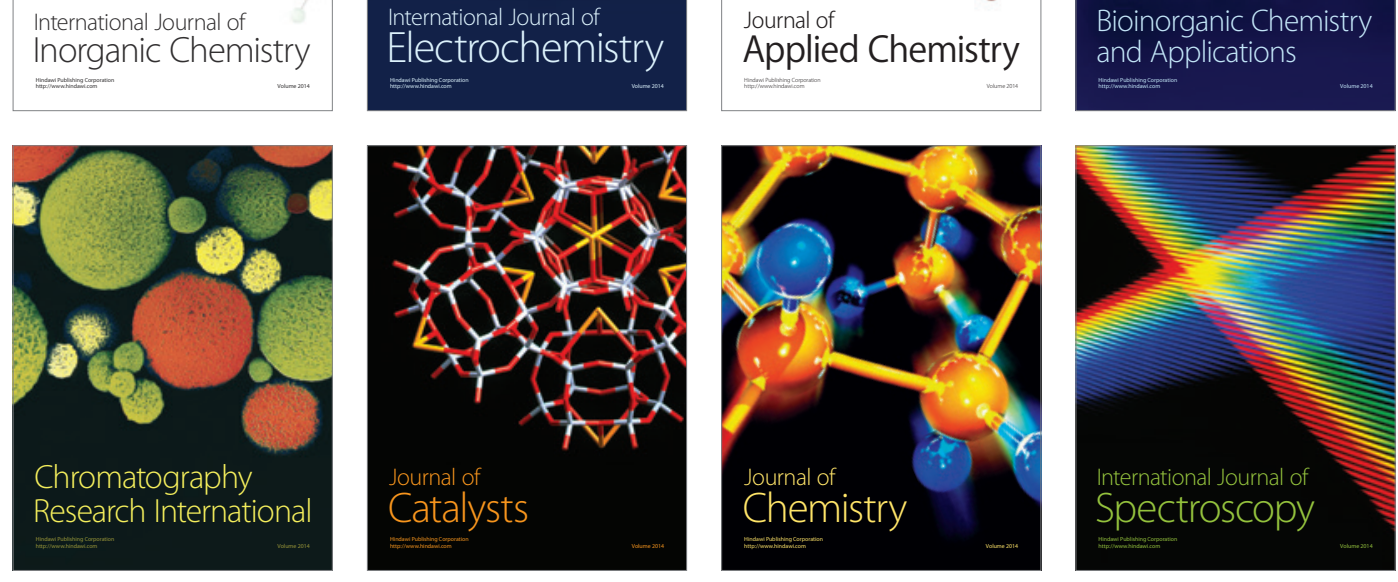